\title{
THE HEMODYNAMIC RESPONSE TO EXERCISE IN PATIENTS WITH LAENNEC'S CIRRHOSIS ${ }^{1}$
}

\author{
By WALTER H. ABELMANN, ${ }^{2}$ HENRY J. KOWALSKI, ${ }^{3}$ AND WILLIAM F. MCNEELY \\ (From the Thorndike Memorial Laboratory, Second and Fourth Medical Services (Harvard), \\ Boston City Hospital, and the Department of Medicine, Harvard Medical School, \\ Boston, Mass.)
}

(Submitted for publication July 14, 1954; accepted August 5, 1954)

Previous studies in this laboratory have shown that some patients with chronic alcoholism and Laennec's cirrhosis at rest in the supine position have a high cardiac output and low peripheral vascular resistance (1). The cardiac output in such subjects is increased out of proportion to the oxygen consumption, i.e., the arteriovenous oxygen difference is unusually small.

The present study of the hemodynamic response to exercise in patients with Laennec's cirrhosis was carried out to assess the cardiac reserve, and to determine whether individuals with elevated cardiac output and lowered peripheral vascular resistance at rest are capable of further decrease in peripheral resistance during exercise.

\section{MATERIAL AND METHODS}

Eleven patients with advanced Laennec's cirrhosis were studied on seventeen separate occasions at rest and during exercise. The patients were selected on the basis of availability and consent, and absence of clinical, radiographic, and radioscopic evidence of coexisting organic disease of the heart or lungs. All gave a history of excessive intake of alcohol of long duration, associated with irregular eating habits. The diagnosis of cirrhosis was made on the basis of history, hepatomegaly, associated secondary signs such as spider angiomata, palmar erythema, decreased axillary and pubic hair, evidence of portal hypertension and laboratory evidence of hepatic dysfunction. In one patient (Case No. 23) the diagnosis was confirmed by needle biopsy of the liver, and in two others (Cases No. 21 and No. 38) at postmortem examination. Of the eleven patients studied, eight had overt ascites and/or edema at the time of the first study, while three showed no evidence of fluid retention. About half of the patients were mildly to moderately anemic. In no instance was there evidence of recent bleeding.

1 Aided by a grant from the Massachusetts Heart Association.

2 This work was done in part during the tenure of a Research Fellowship of the American Heart Association.

3 This work was carried out during the tenure of a Postdoctoral Research Fellowship, Life Insurance Medical Research Fund.
None of the patients showed clinical evidence of thiamine deficiency. Three patients (Nos. 21, 28, and 31) had been taking thiamine for several weeks prior to study. Some of the clinical characteristics are presented in Table I.

The patients were studied in the early morning, in the postabsorptive state, in recumbency and without sedation. The cardiac output was determined by the dye injection method of Hamilton and co-workers (2) with minor modifications as reported previously (1). The dye was injected into an antecubital vein, and samples were taken from a brachial artery. The cardiac index was calculated from the cardiac output and the body surface area based on actual weight at the time of study. It is recognized that in patients with edema and especially ascites body surface area, calculated from height and weight (3), may be an erroneously high index of metabolizing body mass. For this reason, the true cardiac index in patients exhibiting fluid retention may be even higher than reported. Blood flow in relation to metabolic requirements is assessed more validly by the ratio: cardiac output/oxygen consumption, or by its reciprocal, the calculated arteriovenous oxygen difference.

Oxygen consumption in general was determined by the open circuit method, the expired air being collected in a Douglas bag over a three-minute period. During the second minute the cardiac output was determined. The volume of expired air was measured in a Tissot spirometer. The concentration of oxygen was measured by means of a Pauling Oxygen Analyzer. ${ }^{*}$ The average R.Q. corrections of Dexter and his co-workers (4) for converting expired volume to inspired volume were used. In patients No. 23 and No. 28A the oxygen consumption was determined by means of a closed circuit water spirometer filled with oxygen, over a six-minute period, after each determination of the cardiac output.

Phasic and mean arterial pressures were measured directly by means of an electro-manometer ${ }^{5}$ and recorded on a direct writing oscillograph. 5

Peripheral vascular resistance was calculated according to the formula (5).

Resistance $=$

$\frac{\text { Mean arterial pressure } \mathrm{mm} . \mathrm{Hg} \times 1332}{\text { Cardiac output } \mathrm{cc} . / \mathrm{sec} \text {. }}$

dynes seconds $\mathrm{cm} .^{-5}$

The studies were then repeated during mild exercise,

A. O. Beckman, Inc., Pasadena, California.

- Sanborn Company, Cambridge, Massachusetts. 
HEMODYNAMICS DURING EXERCISE IN CIRRHOSIS

".

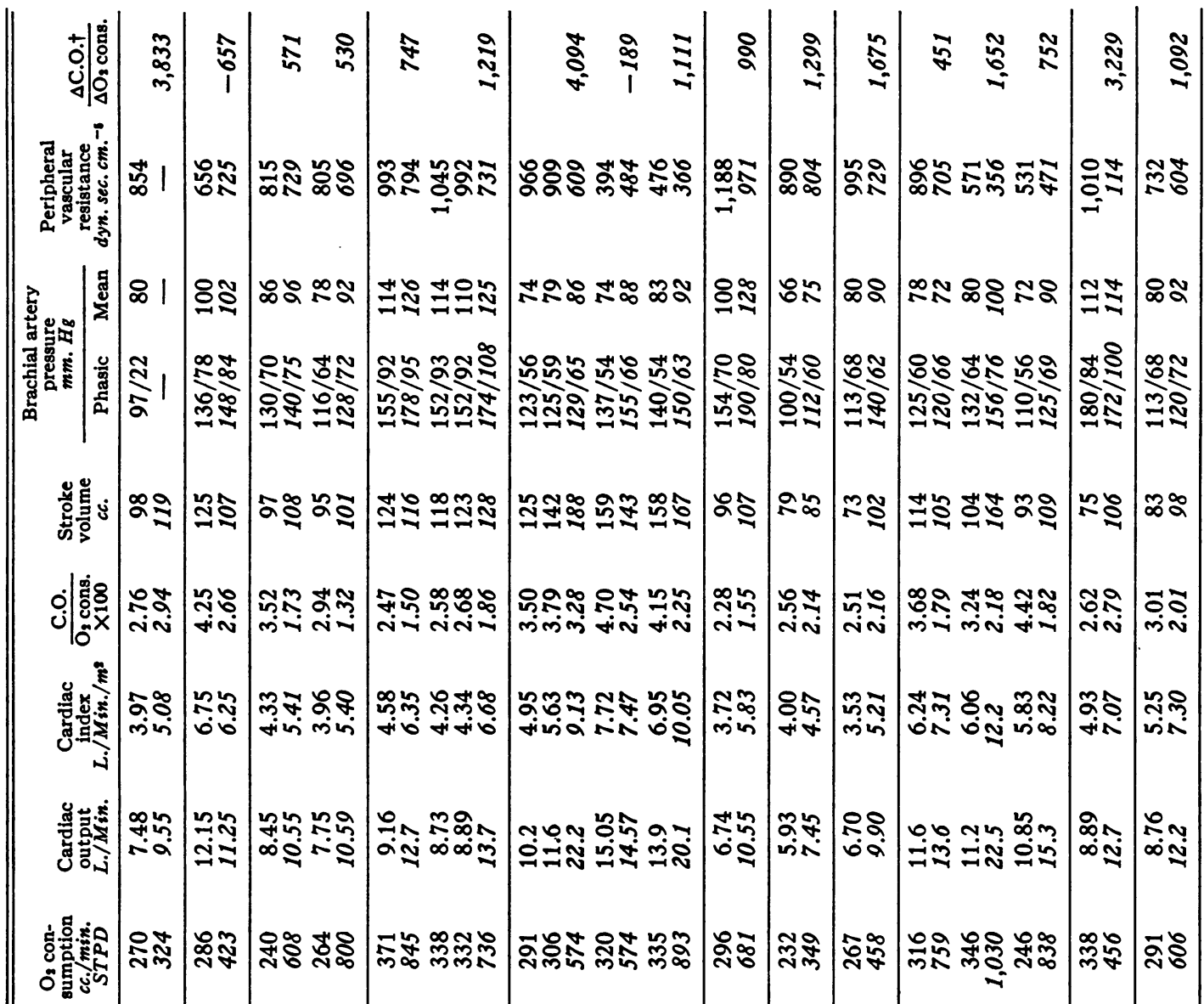

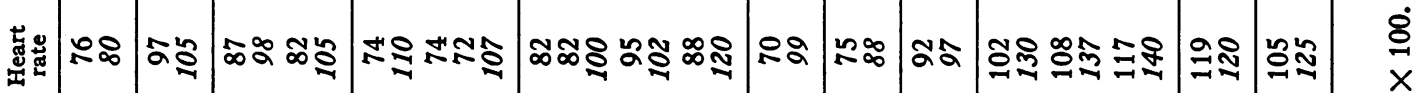

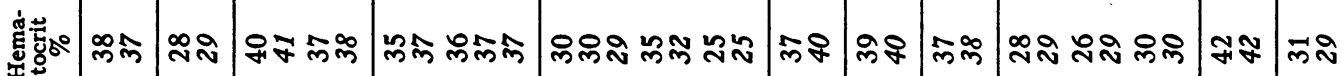

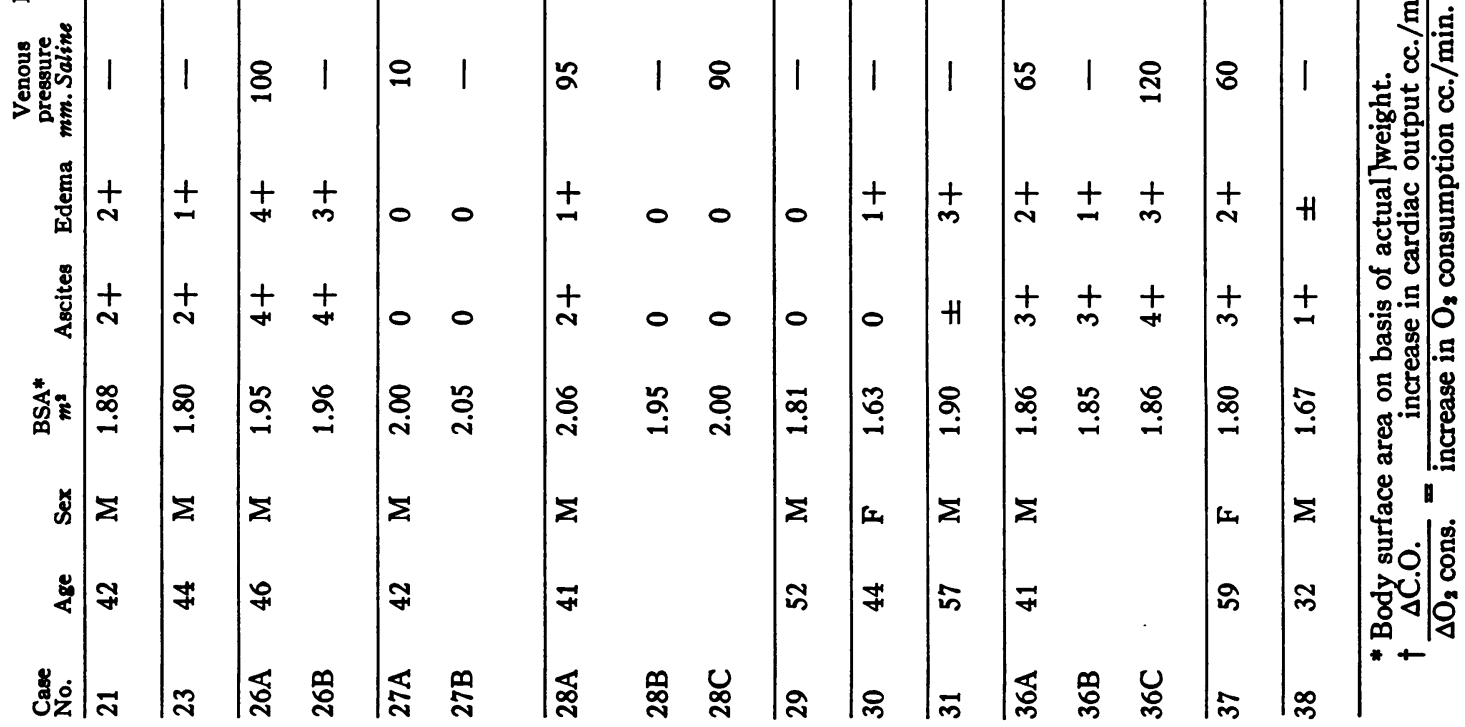


performed by pedalling on a bicycle ergometer at an approximate rate of 40 to 50 r.p.m., in recumbency. External work was not measured; the increase of the oxygen consumption served as an index of work performed. A minimum of ten minutes of steady exercise was required before the simultaneous determinations of cardiac output and oxygen consumption were carried out.

In seven instances the antecubital venous pressure at rest was estimated by means of a saline manometer, with reference to a zero point $5 \mathrm{~cm}$. below the angle of Louis.

\section{RESULTS}

The data are presented in Table I. The observations made in patient No. 21 at rest have been reported previously (1: Case No. 21).

\section{Observations at rest}

Twenty-four normal subjects studied at rest in this laboratory (6) have shown a mean cardiac index of 3.60 per Min. per $\mathrm{m}^{2}$ with a standard deviation of $\pm 0.62 \mathrm{~L}$. per Min. per $\mathrm{m}^{2}$. The findings in the present series of patients with cirrhosis are similar to those in a previous group of comparable patients (1). The mean resting cardiac index in the present group of cirrhotic patients was $5.14 \mathrm{~L}$. per Min. per $\mathrm{m}^{2}$, with a standard deviation of $\pm 1.27 \mathrm{~L}$. per Min. per $\mathrm{m}^{2}$. In four patients on one or more occasions the cardiac index exceeded $5 \mathrm{~L}$. per Min. per $\mathrm{m}^{2}$; in every instance the cardiac output was elevated out of proportion to the oxygen consumption, hence associated with a small calculated arteriovenous oxygen difference. The blood pressures at rest were within normal limits except for patients No. 27 , No. 29 , and No. 33 whose blood pressure appeared somewhat elevated. The pulse pressure was wide in several patients. Elevated cardiac outputs were associated with relatively low calculated peripheral vascular resistance. The resting heart rate tended to be high but accounted only in part for the increased blood flow, an elevated cardiac output generally being associated with increased stroke volume. No relationship was evident between level of cardiac output and degree of anemia or overt edema or ascites. The venous pressure, where measured, was within normal limits.

\section{The response to exercise}

It was our aim to reach a level of exercise which would result in a two to three-fold increase of the oxygen consumption. While this was accomplished in most patients, others were too weak or were insufficiently motivated to pedal at the necessary pace and reached only about one and one-half times the resting oxygen consumption.

In nine of the eleven patients studied the cardiac output definitely increased during each period of exercise. In these nine patients the increases expressed as increment of blood flow per each $100 \mathrm{cc}$. of increase in oxygen consumption ranged from $451 \mathrm{cc}$. per $100 \mathrm{cc} . \mathrm{O}_{2}$ to $3833 \mathrm{cc}$. per 100 cc. $\mathrm{O}_{2}$, with a mean of $1388 \mathrm{cc}$. per $100 \mathrm{cc} . \mathrm{O}_{2}$. In two patients different responses to exercise were observed. Patient No. 28 showed a very striking increase in blood flow during exercise when first studied, with edema and some ascites, but upon reexamination three months later, when he had returned to work and showed no evidence of fluid retention, he failed to increase his cardiac output during exercise (No. 28B). At both times the level of the resting oxygen consumption and its increment during exercise were comparable. However, the resting cardiac output and stroke volume, which had been only slightly elevated at the time of the first study, were quite high during the second study. Four months later the patient was still jaundiced but had become much more anemic; he was still working steadily. His resting output again was high, but notwithstanding the more marked anemia, the cardiac output at rest was slightly lower than during the second examination. Upon moderate exercise a higher oxygen consumption was reached than previously, and the cardiac output rose from 13.9 liters per Min. to 20.1 liters per Min. (No. 28C). Patient No. 23 was edematous and had an elevated cardiac output at rest. He performed only mild exercise during which the cardiac output did not change significantly. He was not studied again.

The heart rate always increased during exercise.

The stroke volume generally increased. In four studies it decreased slightly (Nos. 23, 27 A, 28B, 36A). In all four instances, both stroke volume and cardiac output were already elevated at rest. In studies No. 23 and No. 28B, the decrease in stroke volume was associated with a slight decrease in cardiac output, in studies No. $27 \mathrm{~A}$ and No. 36A with a slight to moderate increase in cardiac output. 
The mean blood pressure increased during exercise except at the first study of patient No. 36 when it decreased slightly, in association with the smallest increase in blood flow observed in this series.

The calculated peripheral vascular resistance decreased whenever the cardiac output rose during exercise. Only in studies No. 23 and No. 28B, where the cardiac output did not increase, did peripheral resistance also fail to increase.

After the exercise period, each subject was carefully questioned concerning possible symptoms. Although four patients had told of shortness of breath on exertion prior to hospitalization (patients Nos. 21, 29, 33 and 36 A, B, and C), none felt short of breath after the exercise in the laboratory. The exercise was generally considered at least as heavy as walking, and on five occasions the subject felt quite fatigued (patients Nos. 26A, 29, 30, 31, and 36A).

\section{DISCUSSION}

The studies carried out during the resting state confirm our previous hemodynamic observations in patients with Laennec's cirrhosis (1). The cardiac output in certain subjects tends to be increased without a corresponding increase in oxygen consumption, resulting in a narrowing of the arteriovenous oxygen difference. Again, elevation of the resting cardiac output was associated with a lowering of the peripheral vascular resistance.

These findings may be interpreted as indicative of peripheral vascular dilatation analogous to multiple arteriovenous shunts in parallel. The site of the presumed vasodilatation remains in question, although clinical evidence favors the skin (cutaneous spider angiomata, palmar erythema, warm hands, clubbing of fingers), and the finding of decreased hepatic and splanchnic blood flow in Laennec's cirrhosis (7) would tend to eliminate the splanchnic vascular bed. Indeed, plethysmographic evidence of increased cutaneous blood flow in patients with hepatic disease has been reported (8).

Exercise in healthy subjects is accompanied by an increase in cardiac output and a decrease in peripheral vascular resistance, attributed to vasodilatation and opening of new channels of perfusion in the vascular bed of skeletal muscles.
In a group comprising six ambulatory convalescent patients without disease of the heart, lungs or liver and three healthy subjects (6), studied as outlined above, the mean increase in cardiac output during exercise was found to be $505 \mathrm{cc}$. per 100 cc. $\mathrm{O}_{2}$ consumed, with a standard deviation of $397 \mathrm{cc}$. Dexter and associates (4) studied a group of healthy untrained individuals by means of cardiac catheterization and in seven studies with comparable exercise found a mean increment of blood flow of $537 \mathrm{cc}$. per $100 \mathrm{cc}$. $\mathrm{O}_{2}, \pm 356 \mathrm{cc}$. (S.D.). ${ }^{\circ}$

It may be more pertinent to compare the present group of patients to a group of alcohol addicts without evidence of cirrhosis. Ten alcohol addicts, whose mean age was three years below that of the present group of patients, studied in comparable manner, showed a mean resting cardiac index of $3.36 \mathrm{~L}$. per Min. per $\mathrm{m}^{2}$; during exercise the mean increase in blood flow was $703 \mathrm{cc}$. per $100 \mathrm{cc}$. increase in oxygen consumption, with a standard deviation of $107 \mathrm{cc}$. (9). With the exception of studies No. 23 and No. 28B, the increase of the cardiac output of cirrhotic patients during exercise was as great as or greater than that of comparable alcohol addicts without cirrhosis. The cirrhotic patients during exercise showed a mean change in cardiac output of +1318 cc. per $100 \mathrm{cc}$. increase in oxygen consumption, with a standard deviation of $1300 \mathrm{cc}$.

The greater mean increase in blood flow in the exercising cirrhotic subjects, as compared to other subjects studied in this laboratory, is difficult to evaluate in view of the greater variability of response in the cirrhotic group. Considerable variation in the response of normal subjects to exercise has been reported from other laboratories $(10,11)$. Nevertheless, the present data suggest that in cirrhosis the cardiac output during exercise, as well as the cardiac output at rest, may be unusually high.

The failure of patient No. 28 to respond to exercise by an increase in cardiac output at the time of the second study (No. 28B) may well be related to the high level of his resting blood flow. At rest his calculated arteriovenous oxygen difference was small, while during mild exercise it fell within normal range. Thus in proportion to

- Values computed by us. 
the oxygen consumption, blood flow remained normal. Since the mean arterial pressure rose during exercise, left ventricular work against pressure actually increased. In a third study (No. 28C), the same patient during more strenuous exercise exhibited an adequate increase in cardiac output. Thus it appears unlikely that cardiac reserve was limited at the time of the second study. Patient No. 23 performed only very mild exercise. Inasmuch as his resting blood flow also was elevated, his calculated arteriovenous oxygen difference was normal during exercise despite his failure to increase blood flow.

A situation similar to that encountered in patients 23 and $28 \mathrm{~B}$ has been observed in patients with anxiety studied at rest and during mild exercise $(6,12)$. When anxiety was accompanied by a high resting blood flow cardiac output during subsequent exercise at times failed to increase further, or even fell below the resting level.

It is of interest that tense abdominal ascites, present in subjects $26 \mathrm{~A}, 26 \mathrm{~B}$, and $36 \mathrm{C}$, did not prevent a moderate rise in blood flow during exercise.

On the whole the response of the present series of patients with chronic alcoholism and Laennec's cirrhosis to mild and moderate exercise may be considered within normal limits. In general our patients were able to increase cardiac output and were capable of further vasodilatation or perfusion of additional vascular channels during exercise. The tendency of blood flow to be increased out of proportion to oxygen consumption at rest tended to persist or even increase during exercise.

Under the conditions of study; the present patients were able to meet an increased demand for oxygen by increasing cardiac output and showed no evidence of a decrease in cardiac reserve. Thus, although the incidence of "high output state" was high, there was no evidence of "high output failure," as has been described in beriberi heart disease (13-15). However, the hemodynamic response of such patients to maximal exercise, and the end-diastolic ventricular pressure during exercise remain unknown.

\section{SUMMARY}

Cardiac output, direct arterial pressure, and oxygen consumption were measured in eleven patients with Laennec's cirrhosis on seventeen separate occasions at rest and during mild to moderate exercise in the supine position.

At rest, the cardiac output was often high and associated with a low peripheral vascular resistance. During exercise the cardiac output increased and peripheral resistance decreased in all but two instances. The increase in blood flow generally was at least of the order of that seen in normal individuals during comparable exercise and often was quite large.

\section{ACKNOWLEDGMENT}

We are very grateful to Dr. Laurence B. Ellis for his interest and valuable advice, and to Miss Vilma Grube for her technical assistance.

\section{REFERENCES}

1. Kowalski, H. J., and Abelmann, W. H., The cardiac output at rest in Laennec's cirrhosis. J. Clin. Invest., 1953, 32, 1025.

2. Hamilton, W. F., Riley, R. L., Attyah, A. M., Cournand, A., Powell, D. M., Himmelstein, A., Noble, R. P., Remington, J. W., Richards, D. W., Jr., Wheeler, N. D., and Witham, A. C., Comparison of the Fick and dye injection methods of measuring the cardiac output in man. Am. J. Physiol., 1948, 153, 309.

3. DuBois, D., and DuBois, E. F., Clinical calorimetry. $\mathrm{X}$. A formula to estimate the approximate surface area if height and weight be known. Arch. Int. Med., 1916, 17, 863.

4. Dexter, L., Whittenberger, J. L., Haynes, F. W., Goodale, W. T., Gorlin, R., and Sawyer, C. G., Effect of exercise on circulatory dynamics of normal individuals. J. Applied Physiol., 1951, 3, 439.

5. Cournand, A., Riley, R. L., Bradley, W. E., Breed, E. S., Nobel, R. P., Lauson, H. D., Gregersen, M. I., and Richards, D. W., Studies of the circulation in clinical shock. Surgery, 1943, 13, 964.

6. Kowalski, H. J., Abelmann, W. H., McNeely, W. F., Frank, N. R., and Ellis, L. B., The cardiac output of normal subjects determined by the dye-injection method at rest and during exercise. Am. J. M. Sc., 1954, 228, 622.

7. Bradley, S. E., Ingelfinger, F. J., and Bradley, G. P., Hepatic circulation in cirrhosis of the liver. Circulation, 1952, 5, 419.

8. Abramson, D. I., and Lichtman, S. S., Influence of ergotamine tartrate upon peripheral blood-flow in subjects with liver disease. Proc. Soc. Exper. Biol. \& Med., 1937, 37, 262.

9. Abelmann, W. H., Kowalski, H. J., and McNeely, W. F., Studies of the circulation in alcohol addicts. 
The cardiac output at rest and during moderate exercise. Quart. J. Stud. on Alcohol, 1954, 15, 1.

10. Chapman, C. B., and Fraser, R. S., Studies on the effect of exercise on cardiovascular function. I. Cardiac output and mean circulation time. Circulation, 1954, 9, 57.

11. Asmussen, E., and Nielsen, M., The cardiac output in rest and work determined simultaneously by the acetylene and the dye-injection methods. Acta physiol. Scandinav., 1953, 27, 217.

12. Hickam, J. B., Cargill, W. H., and Golden, A., Cardiovascular reactions to emotional stimuli. Effect on the cardiac output, arteriovenous oxygen difference, arterial pressure, and peripheral resistance. J. Clin. Invest., 1948, 27, 290.

13. Burwell, C. S., and Dexter, L., Beriberi heart disease. Tr. A. Am. Physicians, 1947, 60, 59.

14. Campbell, J. A., Selverstone, L. A., and Donovan, D. L., Studies on the high output cardiac failure of occidental beriberi. J. Clin. Invest., 1951, 30, 632.

15. Lahey, W. J., Arst, D. B., Silver, M., Kleeman, C. R., and Kunkel, P., Physiologic observations on a case of beriberi heart disease, with a note on the acute effects of thiamine. Am. J. Med., 1953, 14, 248. 